\title{
LETTER
}

\section{Effect of recruitment maneuver on hypoxemia during apnea test: after or before?}

\author{
Evren Senturk* and Nahit Cakar \\ See related research by Paries et al., http://ccforum.com/content/16/4/R116
}

We read with interest the article entitled 'Benefit of a single recruitment maneuver after an apnea test for the diagnosis of brain death' by Paries and colleagues [1].

The 'ideal' apnea test (AT) should permit an increase in $\mathrm{PaCO}_{2}$ (partial pressure of carbon dioxide in arterial blood) but prevent a detrimental decrease in $\mathrm{PaO}_{2}$ (partial pressure of oxygen in arterial blood). We agree that a recruitment maneuver (RM) after the AT can improve oxygenation and result in protection of donor organs. However, we have two comments.

First, changes in $\mathrm{PaCO}_{2}$ are not reported in the article. It has been shown that $\mathrm{RM}$ can affect $\mathrm{CO}_{2}$ elimination in different ways [2]. We think that the course of - already elevated - $\mathrm{PaCO}_{2}$ after RM would be of interest, and may also have clinical consequences. The structure of the study is appropriate to report the changes in $\mathrm{PaCO}_{2}$.

Second, we have shown in an animal model that a RM prior to AT followed by apneic oxygenation was associated with an increase in $\mathrm{PaO}_{2}$ without affecting the increase in $\mathrm{PaCO}_{2}$ [3]. RM plus apneic oxygenation also improved the survival time during AT, and there was no change in $\mathrm{PaCO}_{2}$ (which is a warranted result).

We think that the 'optimal' method for the AT should also consider changes in $\mathrm{PaCO}_{2}$. A RM before (likewise after) the AT could prevent hypoxemia. Whether a 'combination' of RM's before and after the AT would have additive effects should also be examined in further clinical studies.

\section{Abbreviations}

AT, apnea test; $\mathrm{PaCO}_{2}$, partial pressure of carbon dioxide in arterial blood; $\mathrm{PaO}_{2}$, partial pressure of oxygen in arterial blood; RM, recruitment maneuver.

\section{Competing interests}

The authors declare that they have no competing interests.

\section{Published: 11 December 2012}

\section{References}

1. Paries M, Boccheciampe N, Raux M, Riou B, Langeron O, Nicolas-Robin A: Benefit of a single recruitment maneuver after an apnea test for the diagnosis of brain death. Crit Care 2012, 16:R116.

2. Tusman G, Bohm SH, Suarez-Sipmann F, Scandurra A, Hedenstierna G: Lung recruitment and positive end-expiratory pressure have different effects on CO2 elimination in healthy and sick lungs. Anesth Analg 2010, 111:968-977.

3. Senturk E, Tanju S, Ziyade S, Ozcan PE, Tugrul S, Cakar N: A recruitment maneuver improves apneic oxygenation. Minerva Anestesiol 2011, 77:598-603.

doi:10.1186/cc11873

Cite this article as: Senturk E, Cakar N: Effect of recruitment maneuver on hypoxemia during apnea test: after or before? Critical Care 2012, 16:469.

*Correspondence: evrensenturk2@yahoo.com

Istanbul University, Istanbul Medical Faculty, Department of Anesthesiology, Capa-Fatih, 34093 Istanbul, Turkey 